Marquette University

e-Publications@Marquette

5-23-2014

\title{
Alexithymia Impairs the Cognitive Control of Negative Material While Facilitating the Recall of Neutral Material in Both Younger and Older Adults
}

\author{
Déborah Dressaire \\ Université Paul Valéry - Montpellier III \\ Charles B. Stone \\ John Jay College of Criminal Justice \\ Kristy A. Nielson \\ Marquette University, kristy.nielson@marquette.edu \\ Estelle Guerdoux \\ Université Paul Valéry - Montpellier III \\ Denis Brouillet \\ Université Montpellier III
}

See next page for additional authors

Follow this and additional works at: https://epublications.marquette.edu/psych_fac

Part of the Psychology Commons

\section{Recommended Citation}

Dressaire, Déborah; Stone, Charles B.; Nielson, Kristy A.; Guerdoux, Estelle; Brouillet, Denis; and Luminet, Olivier, "Alexithymia Impairs the Cognitive Control of Negative Material While Facilitating the Recall of Neutral Material in Both Younger and Older Adults" (2014). Psychology Faculty Research and Publications. 126.

https://epublications.marquette.edu/psych_fac/126 


\section{Authors}

Déborah Dressaire, Charles B. Stone, Kristy A. Nielson, Estelle Guerdoux, Denis Brouillet, and Olivier Luminet 


\section{Alexithymia Impairs the Cognitive Control of Negative Material While Facilitating the Recall of Neutral Material in Both Younger and Older Adults}

Déborah Dressaire

Service de Gérontologie et prévention du vieillissement, Centre Raymond Ruffi, Université Paul Valéry - Montpellier III, Montpellier, France

Charles B. Stone

Department of Psychology, John Jay College of Criminal Justice, New York, NY

Psychological Sciences Research Institute,

Université catholique de Louvain,

Louvain-la-Neuve, Belgium

Kristy A. Nielson

Department of Neurology, Medical College of Wisconsin,

Milwaukee, WI

Department of Psychology, Marquette University,

Milwaukee, WI 


\author{
Estelle Guerdoux \\ Clinique du Millénaire, Laboratoire Epsylon, \\ Université Paul Valéry - Montpellier III, \\ Montpellier, France \\ Sophie Martin \\ Laboratoire Epsylon, Université Montpellier III \\ Montpellier, France \\ Denis Brouillet \\ Laboratoire Epsylon, Université Montpellier III \\ Montpellier, France \\ Olivier Luminet \\ Psychological Sciences Research Institute, \\ Université catholique de Louvain, \\ Louvain-la-Neuve, Belgium \\ Belgian Fund for Scientific Research (FRS-FNRS), \\ Brussels, Belgium
}

\begin{abstract}
We investigated the moderating impact of the personality construct alexithymia on the ability of younger and older adults to control the recall of negative and neutral material. We conducted two experiments using the directed forgetting paradigm with younger and older adults. Participants studied negative (Experiment 1) or neutral (Experiment 2) words. Participants were instructed to forget the first half and remember the second half of an entire list of words. Overall, we found that alexithymia impairs the ability of both younger and older adults to cognitively control negative material (through both recall and inhibition). The "externally oriented thinking" factor of alexithymia appears to play a particularly pertinent role in terms of inhibiting negative material. Furthermore, older adults recalled fewer sought after negative items, but this was not evident in terms of inhibition. In contrast, only age (older adults) negatively impacted the recall of sought after neutral items. Interestingly, alexithymia had the opposite effect: the "difficulty in identifying emotions" factor of alexithymia was associated with an increased recall of neutral items. We discuss these results in terms of alexithymia and its impact on cognitive control.
\end{abstract}

Keywords: Age, Alexithymia, Cognitive control, Directed forgetting, Emotion, Externally oriented thinking, Negative, Neutral, Recall 
Recently, there has been a dramatic increase in research examining emotional processing and ageing (see, e.g., Carstensen \& Mikels, 2005; Charles \& Carstensen, 2007). In particular, much research has shown how adults exhibit marked improvements in emotional regulation over time (Gross et al., 1997). Researchers have argued that such improvements in mental health and emotional regulation may stem from the ability of older adults to focus on positive stimuli/memories while ignoring negative ones, a phenomenon known as the "positivity effect" (Charles, Mather, \& Carstensen, 2003; Mather \& Carstensen, 2005; Mather \& Knight, 2005). This research suggests that the ability of older adults to ignore unwanted negative memories may be critical towards maintaining psychological well-being (see Carstensen \& Mikels, 2005). It is likely, however, that some individual differences might influence the ability of older adults to control the accessibility of negative memories. One such individual difference is alexithymia.

Alexithymia is a multifaceted personality construct defined as a difficulty in experiencing and expressing emotions (Sifneos, 1973). This construct comprises three principal factors: (1) difficulties in identifying feelings and distinguishing them from bodily sensations of emotional arousal (DIF); (2) difficulties in describing one's own feelings (DDF); and (3) a stimulus-bound, externally oriented cognitive style (i.e., operational thinking; EOT), i.e., focusing one's attention externally with little internal inspection or insight (Nemiah, Freyberger, \& Sifneos, 1976). In the past, there have typically been two approaches towards examining alexithymia: as a categorical or continuous construct. Initially, alexithymia was operationalised as a clinical category: individuals are either alexithymic or they are not, according to a clinical cut-off score. However, more recently, researchers have begun operationalising alexithymia as a continuous construct that varies among all individuals (Taylor, Bagby, \& Parker, 1997). While the former view dominated the field of alexithymia early on, there is now a growing consensus among researchers that the latter operationalisation best captures the ubiquity of alexithymic tendencies in the general public. The present research adopts the latter approach.

Researchers have long acknowledged the importance of alexithymia in conjunction with ageing, indicating an increased 
severity of alexithymia in older age (Feiguine, Hulihan, \& Kinsman, 1982; Gunzelmann, Kupfer, \& Brähler, 2002; Krystal, 1995; Mattila, Salminen, Nummi, \& Joukamaa, 2006; Paradiso, Vaidya, McCormick, Jones, \& Robinson, 2008; Pasini, Chiaie, Seripa, \& Ciani, 1992). Despite this, researchers have yet to examine how alexithymia may influence the healthy mental functioning and emotional regulation adults exhibit as they grow older (i.e., the "positivity effect"). That is, alexithymia may prevent older adults from effectively ignoring, or having cognitive control over unwanted negative memories.

\section{Alexithymia and cognitive control}

Studies have shown that alexithymia impacts the cognitive processing of emotional information. For example, Luminet, Vermeulen, Demaret, Taylor, and Bagby (2006) conducted a study of long-term memory using the remember/know procedure while manipulating how deeply the individuals encoded the information. Those with higher alexithymia scores consciously recollected ("remember") fewer emotional words compared to neutral words. Similarly, Meltzer and Nielson (2010) found that those with higher alexithymia scores demonstrated poorer long-term retrieval of negative emotion words compared to those with lower alexithymia scores. Both sets of investigators concluded that alexithymia was related to deficits in consciously recollecting some, but not necessarily all, emotional material (see also Montreuil \& Pedinielli, 1995; Suslow, Kersting, \& Arolt, 2003, but see Jacob \& Hautekeete, 1998; Lundh, Johnsson, Sundqvist, \& Olsson, 2002, Study 1).

However, the extent to which alexithymia moderates cognitive control/memory performance may be the result of one of the specific factors comprising alexithymia. Unfortunately, the research examining the impact of specific alexithymic factors is mixed. For example, Luminet et al. (2006) found that the ability to recall positive or negative material was predicted equally by the three different alexithymia factors. Similarly, Vermeulen, Toussaint, and Luminet (2010) found no differences across the factors in predicting recognition rates when primed with either congruent or incongruent emotional music during encoding. However, they did find a stronger negative correlation between recognition of anger words, when primed with 
happy music, for the EOT factor of alexithymia (see also Luminet, Rime, Bagby, \& Taylor, 2004; Nielson, 2012). Vermeulen and Luminet (2009) even found a possible mnemonic benefit associated with EOT. Overall, the results of previous literature are not consistent: some studies find a specific cognitive influence for one alexithymia factor, while others suggest the involvement of all three. Thus, it is critical to further examine this issue.

Furthermore, while those with higher alexithymia scores have greater difficulty recalling emotional material, researchers have yet to examine how alexithymia may influence the ability to intentionally not recall (i.e., inhibit) unwanted emotional material. Such studies are imperative as they will begin to provide a more holistic understanding of the cognitive processes involved when adults with higher levels of alexithymia attempt to control the recall of negative material. Importantly, it may also help lead to possible treatments for adults having difficulty regulating their emotions. Therefore, to address age effects in alexithymia and cognitive control, we used the directed forgetting paradigm with younger and older adults (see, e.g., MacLeod, 1998, 1999; Power, Dalgleish, Claudio, Tata, \& Kentish, 2000).

\section{Directed forgetting}

The directed forgetting paradigm is commonly used to examine the extent to which individuals can voluntarily control the retrieval of memoranda that are instructed as either "to-be-remembered" (TBR) or "to-be-forgotten" (TBF) information. Thus, it examines the ability to "control the contents of consciousness" (Whetstone, Cross, \& Whetstone, 1996). Two methods are commonly used (Basden \& Basden, 1996; Basden, Basden, \& Gargano, 1993; MacLeod, 1998, 1999): (1) the item-by-item cueing method (i.e., word method), which tends to induce rehearsal mechanisms during encoding and (2) the list cueing method (i.e., list method), where "forget" instructions are provided after the first half of the list and "remember" instructions occur after the second half, which requires a specific effort to forget and/or control for context changes. As we were interested in the latter form of cognitive control, we used the list method in our study. The list method (e.g., MacLeod, 1998, 1999; Zellner \& Bäuml, 2006) assesses

Cognition and Emotion, Vol 28 (May 23, 2014): pg. 442-459. DOI. This article is (c) Taylor \& Francis (Routledge) and permission has been granted for this version to appear in e-Publications@Marquette. Taylor \& Francis (Routledge) does not grant permission for this article to be further copied/distributed or hosted elsewhere without the express permission from Taylor \& Francis (Routledge). 
cognitive control either through intentional efforts to remember and forget (see also Bjork, Bjork, \& Anderson, 1998) or through efforts to change one's mental context (Sahakyan, Delaney, \& Goodmon, 2008; Sahakyan \& Foster, 2009; Sahakyan \& Kelley, 2002). More specifically, it requires an intentional effort to control what is forgotten and what is remembered: participants must voluntarily not recall TBF items and voluntarily recall the TBR items (Bjork et al., 1998; Power et al., 2000).

By using the list method directed forgetting paradigm, we will be the first to explicitly examine whether alexithymia moderates the ability of younger and older adults to recall and forget both negative (Experiment 1) and neutral (Experiment 2) material. Our research had five main goals. First, we wanted to examine whether alexithymia scores influence the ability of adults to accurately recall negative TBR and inhibit negative TBF items. Second, we wanted to examine whether age influences the ability of individuals to inhibit unwanted, negative memories (i.e., the TBF items), as the literature is unclear about what to expect with negative material; on the one hand, decreased cognitive control in advanced age might lead to an inability to inhibit negative TBF items and a decreased ability to actively recall negative TBR items (e.g., Dywan \& Murphy, 1996; Hasher, Zacks, \& May, 1999; Jacoby, Bishara, Hessels, \& Toth, 2005; Zacks, Hasher, \& Radvansky, 1996, but see Zellner \& Bäuml, 2006). On the other hand, the literature examining the "positivity effect" suggests older adults should exhibit an increased ability to inhibit the recall of negative TBF intrusions and a decreased ability to actively recall negative TBR items (Charles et al., 2003; Mather \& Carstensen, 2005; Mather \& Knight, 2005).

Third, we sought to examine whether the effects of alexithymia on cognitive control for negative material are driven generally or primarily by one or more of the three alexithymic factors. Only a few studies have examined the influence of the individual factors of alexithymia (see, e.g., Vermeulen \& Luminet, 2009), and they have provided contradictory results: either finding no difference across factors or finding that the EOT factor of alexithymia influences the ability of individuals to recall certain memories and, in some cases, leading to mnemonic benefits (Vermeulen \& Luminet, 2009). We hope to further clarify this discrepancy. permission has been granted for this version to appear in e-Publications@Marquette. Taylor \& Francis (Routledge) does not grant permission for this article to be further copied/distributed or hosted elsewhere without the express permission from Taylor \& Francis (Routledge). 
Fourth, we wanted to examine whether the sum score of the TAS-20 and/or the three factors comprising the TAS-20 scale were greater in older age as has been previously reported (Pasini et al., 1992).

Lastly, we examined whether alexithymia and age effects on cognitive control would differ with negative material vs. neutral material because, overall, the literature suggests that alexithymia may have less of an effect on neutral material than emotionally valent material (Parker, Taylor, \& Bagby, 1993; see also Luminet et al., 2006).

\section{Experiment 1}

Below, we report how we determined our sample size, all participants who were excluded, all manipulations and all measures in the study.

\section{Method}

\section{Participants and design}

Sixty adults (ages ranged from 35 to $99 ; N=30$ women) were recruited from various fitness centres and nursing homes in the south of France (Dressaire \& Brouillet, 2006). Sixty adults were recruited to participate in this study, a sample size consistent with and/or that exceeds previous studies examining directed forgetting in younger and older adults (see, e.g., Zacks et al., 1996; Zellner \& Bäuml, 2006). Most of our younger adults were recruited from fitness centres whereas we recruited most of our older adults from nursing homes. We return to the issues surrounding such a recruitment process in the General Discussion section. Screening criteria for inclusion in the study included adults (younger and older) with normal scores (total $>27$ ) on the Mini-Mental State Examination (MMSE, which evaluates global cognitive efficiency; Derouesné et al., 1999) and the Hospital Anxiety Depression Scale (HADS, total score $\leq 12$; Cronbach's $a=.20^{2}$; Friedman, Samuelian, Lancrenon, Even, \& Chiarelli, 2001; Lepine, 1985). Thus, all of our participants scored within the healthy range on both MMSE $(M=28.73, S D=1.12)$ and $\operatorname{HADS}(M=9.57, S D=2.8)$. 
In order to examine whether there were any substantive differences between younger and older adults in these scores, we created a median split and compared them across age groups: we found no significant differences, $t(58)=1.20, p=.24$ and $t(58)=.05, p=.95$, respectively (see Table 1 ). Additionally, participants selected for inclusion also demonstrated intact cognitive ability in the domains of verbal fluency, memory span and speed of processing as measured by the RL/RI 16 items (Van der Linden et al., 2004) and the Trail-Making Tests (Tombaugh, 2004).

Table 1. Experiment 1: Descriptive statistics (mean [SD]) according to age group

Younger adults

$\begin{array}{lll}\text { Age }(y r s) & 40.96(5.29) * * & 86.30(6.73) * * \\ \begin{array}{l}\text { Education } \\ \text { (yrs) }\end{array} & 9.35(2.47) & 8.33(2.27) \\ \text { MMSE } & 28.73(1.33) & 28.74(1.07) \\ \text { HADS } & 10.00(3.15) & 9.17(3.17) \\ \text { TAS-20 } & 45.00(7.15) * * & 57.53(6.64) * * \\ \text { total } & & \\ \text { DIF } & 13.83(5.97) * * & 18.43(6.94) * * \\ \text { DDF } & 13.70(5.78) & 14.80(4.62) \\ \text { EOT } & 17.73(4.40) * * & 25.00(4.98) * *\end{array}$

MMSE, Mini-mental State Exam; HADS, Hospital Anxiety Depression Scale; TAS-20 total, Toronto Alexithymia Scale-20, total score; DIF, difficulties in identifying feelings and distinguishing them from bodily sensations of emotional arousal, Alexithymia Factor 1; DDF, difficulties in describing one's own feelings, Alexithymia Factor 2; and EOT, a stimulus-bound, externally oriented cognitive style (i.e., operational thinking), Alexithymia Factor 3.

** Denotes significance across groups lower than the .01 level.

We measured alexithymia using the 20-item Toronto Alexithymia Scale (TAS-20; Bagby, Parker, \& Taylor, 1994; Bagby, Taylor, \& Parker, 1994; Loas et al., 1996). The TAS-20 was used in its validated French translation (Loas et al., 1996; Cronbach's $a=.80$ ). The reliability and validity of the TAS-20 has been demonstrated in numerous samples (Loas, Parker, Otmani, Verrier, \& Fremaux, 1997; Loas et al., 2001; Parker, Taylor, \& Bagby, 2003; Taylor, Bagby, \& Parker, 2003; Taylor, Bagby, \& Luminet, 2000). The average alexithymia score was $51.75(S D=15.08)$ and ranged from 24 to 84 (see Table 1). 
Furthermore, as expected based on previous research (Pasini et al., 1992), we found a significant difference across the two age groups in terms of sum total TAS-20 scores, $t(58)=3.67, d=0.95, p<.01$, with the older group scoring higher. Notably, this difference was driven by significant differences between the two groups in terms of the DIF and EOT factors of alexithymia, $t(58)=2.75, d=0.56, p<.01$ and $t(58)=6.00, d=0.74, p<.001$, respectively (again, see Table 1 ).

The experimental design consisted of hierarchical regression analyses in order to examine the unique contributions of first age, the sum total alexithymia score and then each of the three alexithymia factors on the recall of TBF and TBR items.

\section{Directed forgetting task}

A set of 18 negative words (Appendix A) was selected from Syssau and Font (2005) norms and divided into two sub-lists of nine words each (sub-lists, Neg1 and Neg2). The words were comparable in printed word frequency, in number of letters and syllables (New, Pallier, Ferrand, \& Matos, 2001), and had no obvious semantic links (Ferrand, 2001; Ferrand \& Alario, 1998). List order was counterbalanced between participants. Words were presented randomly within each list.

\section{Procedure}

The experimenter tested participants individually and informed them that the aim of the experiment was to better understand the cognitive functioning of adults. Our directed forgetting procedure closely followed that of MacLeod's (1999; see also Power et al., 2000). Our set of 18 words was divided into two halves (nine words each). Participants sat in front of a computer screen and were provided each word for two seconds. After the first half (nine words) was presented, participants were instructed to forget ("The aforementioned words were for practice and can be forgotten moving forward."). Participants were then provided the remaining nine words. When all of the remaining nine words were presented, participants were instructed to remember this second set of nine words. In all cases, participants were instructed to forget the first list and remember the second. When

Cognition and Emotion, Vol 28 (May 23, 2014): pg. 442-459. DOI. This article is (C) Taylor \& Francis (Routledge) and permission has been granted for this version to appear in e-Publications@Marquette. Taylor \& Francis (Routledge) does not grant permission for this article to be further copied/distributed or hosted elsewhere without the express permission from Taylor \& Francis (Routledge) 
all of the words had been presented, a free recall test was administered after a one-minute delay. The experimenter encouraged the participants to recall as many of the "remember" words as possible. Upon completion of the free recall test, participants completed the TAS-20 and a demographics sheet before being debriefed about the purposes of our study.

\section{Results and discussion}

We initially analysed the data to examine the possibility of recency or primacy effects by predicting recall according to serial presentation order. Although recall performance was quite low, there were no differences in recall based on serial position: items from the middle of the list were just as likely to be recalled as early and late items. We also ran a correlational analysis of the pertinent variables (without age, as it is analysed as a dichotomous variable; see Table 3 ). The results of this correlational analysis will be discussed in conjunction with our regression analyses below.

Next, we conducted two sets (one set for TBR items; one set for TBF items) of hierarchical multiple regression analyses: in each set of analyses, one focused on the sum total alexithymia scores, the other on the alexithymia factors (DIF, DDF, EOT). Depression and anxiety scores are often highly correlated with alexithymia scores (Hendryx, Haviland, \& Shaw, 1991). However, given that none of the correlations between depression/anxiety and the other independent variables exceeded .40 (see Table 3), we believe multicollinearity should not be an issue (Voss, 2005). To be safe, though, we still controlled for both of them in our set of regressions. Age was also included in both regressions as a dummy variable (younger vs. older adults). In both sets of regressions, no predictors were taken out later on and all interaction terms were included. To ensure that we met the normality assumptions required for regression analyses, we transformed the data, taking the natural log of each variable prior to analysis.

For the sum total, alexithymia scale hierarchical multiple regression analyses, the variables were entered in three steps. In step 1 , the proportion of TBR or TBF items recalled was entered as the dependent variables, and (1) depression and (2) anxiety scores were entered as independent variables. In step 2, age was entered into the 
step 1 equation. In step 3, we entered the sum total alexithymia scores (see Table 2 for the means and standard deviations according to TBR/TBF items, low/high alexithymia and age).

Table 2. Proportions and standard deviations for recall of negative words according to TBR/TBF items, low/high alexithymia and age

\section{Younger adults}

Older adults

\section{Low alex. High alex.}

Low alex.

High alex.

TBR recall

$0.37(0.14)$

$0.41(0.15)$

$0.31(0.16)$

$0.19(0.17)$

TBF recall

$0.11(0.08)$

$0.13(0.11)$

$0.03(0.05)$

$0.15(0.09)$

TBR, to-be-remembered; TBF, to-be-forgotten; Alex, alexithymia.

The variables in the alexithymia factors hierarchical multiple regression analyses were also entered in three steps. In step 1 , the proportion of TBR or TBF items recalled was entered as the dependent variables, and (1) depression and (2) anxiety scores were entered as independent variables. In step 2, age was entered into the step 1 equation. In step 3, we entered the alexithymia factors: DIF, DDF and EOT (see Table 3 for correlations between all the regression variables).

Table 3. Experiment 1: Correlation values between regression variables for negative material

\begin{tabular}{|c|c|c|c|c|c|c|c|c|}
\hline & 12 & 3 & 4 & 5 & 6 & 7 & 8 & 9 \\
\hline 1. TBF items recalled & $1-.23$ & $.33 * *$ & -.05 & .17 & .24 & .17 & & .17 \\
\hline 2. TBR items recalled & 1 & $.84 * *$ & -.14 & .23 & $-.43 * *$ & $-.31 *$ & -.23 & $-.53 * *$ \\
\hline 3. Total items recalled & & 1 & -.17 & $.31 *$ & $-.28 *$ & -.21 & -.06 & $-.41 * *$ \\
\hline 4. Anxiety scores & & & 1 & -.15 & $.37 * *$ & $.39 * *$ & $.31 * *$ & .14 \\
\hline 5. Depression scores & & & & 1 & -.21 & -.17 & -.09 & $-.27 *$ \\
\hline 6. TAS Total score & & & & & 1 & $.91 * *$ & $.81 * *$ & $.79 * *$ \\
\hline 7. DIF & & & & & & 1 & $.67 * *$ & $.57 * *$ \\
\hline 8. DDF & & & & & & & 1 & $.40 * *$ \\
\hline 9. EOT & & & & & & & & 1 \\
\hline
\end{tabular}

Note: We computed a Split-Half score to examine the reliability of these results. We found good reliability with a Spearman-Brown Coefficient of .71.

DIF, difficulties in identifying feelings and distinguishing them from bodily sensations of emotional arousal, Alexithymia Factor $1 ;$ DDF, difficulties in describing one's own feelings, Alexithymia Factor 2; and EOT, a stimulus-bound, externally oriented cognitive style (i.e., operational thinking), Alexithymia Factor 3.

* Denotes significance across groups lower than the .05 level.

** Denotes significance across groups lower than the .01 level.

In terms of TBF intrusions, we found that only the sum total alexithymia scores predicted recall of the negative items (see Table 4). That is, as alexithymia scores increased, intrusion rates also increased.

Cognition and Emotion, Vol 28 (May 23, 2014): pg. 442-459. DOI. This article is (c) Taylor \& Francis (Routledge) and permission has been granted for this version to appear in e-Publications@Marquette. Taylor \& Francis (Routledge) does not grant permission for this article to be further copied/distributed or hosted elsewhere without the express permission from Taylor \& Francis (Routledge). 
Our subsequent hierarchical multiple regression with the alexithymia factors revealed that alexithymia's impact on intrusion rates was driven primarily by EOT: the higher the EOT score, the higher the proportion of TBF intrusions. However, correlational analysis also found a positive association between DDF and intrusion rates (see Table 3). Combined, these results further support the notion that alexithymia should be examined in terms of its factors, not just the global score. We found no interactions of age with either the sum total alexithymia scores or the individual factors (see Table 4).

Table 4. Experiment 1: Regression values with recall of TBF intrusions as the dependent variable for negative material

$\begin{array}{lllllll}\text { Predictors } & \boldsymbol{\beta} & \mathbf{R}^{2} & \mathbf{\Delta R}^{2} & \mathbf{t} & \mathbf{p} \\ \text { Sum total alexithymia } & & & & & \\ \text { Anxiety } & -.10 & .01 & - & -.52 & .60 \\ \text { Depression } & .13 & .02 & .01 & .80 & .43 \\ \text { Age } & -.27 & .02 & .00 & -1.28 & .21 \\ \text { Sum total alexithymia score } & .49 & .15 & .15 & 2.51 & .02 * \\ \text { Sum total alexithymia score } \times \text { Age } & .15 & .17 & .02 & 1.26 & .22 \\ \text { Alexithymia factors } & & & & & \\ \text { Anxiety } & .01 & .01 & - & .06 & .96 \\ \text { Depression } & .17 & .02 & .01 & 1.07 & .29 \\ \text { Age } & -.44 & .05 & .03 & -1.88 & .07 \\ \text { DIF } & -.16 & .14 & .09 & -.61 & .55 \\ \text { DDF } & .16 & .17 & .03 & .61 & .50 \\ \text { EOT } & .64 & .24 & .07 & 2.49 & .02 * \\ \text { DIF } \times \text { age } & .34 & .27 & .03 & .58 & .56 \\ \text { DDF } \times \text { age } & .46 & .28 & .01 & .79 & .43 \\ \text { EOT } \times \text { age } & -.46 & .29 & .01 & -.66 & .52\end{array}$

DIF, difficulties in identifying feelings and distinguishing them from bodily sensations of emotional arousal, Alexithymia Factor 1; DDF, difficulties in describing one's own feelings, Alexithymia Factor 2; and EOT, a stimulus-bound, externally oriented cognitive style (i.e., operational thinking), Alexithymia Factor 3.

* Denotes significance of the predictor variable lower than the .05 level.

As for recall of TBR items, we found that both the age and the sum total alexithymia scores predicted recall of the negative items: as age and alexithymia increased, the number of recalled negative items decreased (see Table 5). This was also corroborated by our correlation analyses (see Table 3). In our subsequent hierarchical multiple regressions with the alexithymia factors, age remained a significant predictor, but we found no individual alexithymia factor significantly predicted the recall of negative items, suggesting that the negative 
impact of alexithymia on recall is a result of the alexithymia factors together. No individual factor drove the impairment. However, it is worth mentioning that our correlational analysis did reveal a negative association between the recall of TBR items and EOT. These results, again, though, only suggestive, highlight the potentially important influence the EOT factor of alexithymia might have on the retrieval of negatively valenced material. Additionally, we found no interaction of age with either the sum total alexithymia scores or the individual factors.

Table 5. Experiment 1: Regression values with recall of TBR times as the dependent variable for negative material

$\begin{array}{lllllll}\text { Predictors } & \boldsymbol{\beta} & \mathbf{R}^{\mathbf{2}} & \mathbf{\Delta R}^{\mathbf{2}} & \mathbf{t} & \mathbf{p} \\ \text { Sum total alexithymia } & & & & & \\ \text { Anxiety } & .11 & .02 & - & .84 & .40 \\ \text { Depression } & .09 & .04 & .02 & .73 & .47 \\ \text { Age } & -.42 & .21 & .17 & -3.26 & .01 * \\ \text { Sum total alexithymia score } & -.25 & .26 & .05 & -2.00 & .05^{*} \\ \text { Sum total alexithymia score } \times \text { age } & -.14 & .26 & .00 & -1.29 & .24 \\ \text { Alexithymia factors } & & & & & \\ \text { Anxiety } & .07 & .02 & - & .52 & .61 \\ \text { Depression } & .06 & .04 & .02 & -.47 & .64 \\ \text { Age } & -.34 & .26 & .22 & -2.20 & .03 * \\ \text { DIF } & -.07 & .30 & .04 & -.37 & .71 \\ \text { DDF } & -.04 & .31 & .01 & -.22 & .83 \\ \text { EOT } & -.26 & .33 & .02 & -1.48 & .15 \\ \text { DIF } \times \text { age } & .40 & .34 & .01 & .75 & .46 \\ \text { DDF } \times \text { age } & -.74 & .36 & .02 & -1.34 & .19 \\ \text { EOT } \times \text { age } & -.45 & .37 & .01 & -.68 & .50\end{array}$

DIF, difficulties in identifying feelings and distinguishing them from bodily sensations of emotional arousal, Alexithymia Factor $1 ;$ DDF, difficulties in describing one's own feelings, Alexithymia Factor 2; and EOT, a stimulus-bound, externally oriented cognitive style (i.e., operational thinking), Alexithymia Factor 3.

* Denotes significance of the predictor variable lower than the .05 level.

Overall, these results suggest that: (1) scoring higher on alexithymia reduces the ability to voluntarily forget unwanted negative material with the EOT being a particularly important alexithymic factor and (2) higher alexithymia scores and greater age both impair the ability to retrieve sought after negative material. However, we found no interaction between alexithymia and age suggesting that, while alexithymia may increase with age (Feiguine et al., 1982; Gunzelmann et al., 2002; Krystal, 1995; Mattila et al., 2006; Paradiso et al., 2008; 
Pasini et al., 1992), its impact on cognitive control is not a function of age. These results add to the growing literature demonstrating the disruptive nature of alexithymia with negatively valenced material (e.g., Luminet et al., 2006; Meltzer \& Nielson, 2010). Additionally, advanced age appears to assist forgetting of unwanted negative items (though not significantly) while it hinders the ability to retrieve wanted negatively valenced items. While these results appear to contradict directed forgetting research demonstrating the inability of older adults to forget TBF items (e.g., Dywan \& Murphy, 1996; Hasher et al., 1999; Jacoby et al., 2005; Zacks et al., 1996), they support copious amounts of research demonstrating a "positivity effect" in older adults (e.g., Charles et al., 2003; Mather \& Carstensen, 2005; Mather \& Knight, 2005). As such, it is possible that the results of Experiment 1 are due purely to the valence of our material. If this is case, we should not expect the same results with emotionally neutral material. To examine this possibility, we conducted another experiment, identical to the first, but now with neutral words.

\section{Experiment 2}

We used the same apparatus and procedure as in Experiment 1, with the exception of replacing the negative items with neutral items. Again, below, we report how we determined our sample size, all participants who were excluded, all manipulations and all measures in the study.

\section{Method}

Again, 60 adults (ages ranged from 35 to $98 ; N=30$ women) were recruited. As in Experiment 1, all of our participants scored within the healthy range on both HADS $(M=9.97, S D=3.5)$ and MMSE $(M=$ 28.89, $S D=1.29$; Cronbach's $a=.50^{3}$ ). Again, these scores did not vary according to age group, $t(58)=1.63, p=.11$ and $t(58)=.30, p$ $=.77$ (see Table 5). As in Experiment 1, participants selected for inclusion also demonstrated intact cognitive ability in the domains of verbal fluency, memory span and speed of processing as measured by the RL/RI 16 items (Van der Linden et al., 2004) and the Trail-Making Tests (Tombaugh, 2004). The average alexithymia score was 51.02 $(S D=14.61 ;$ Cronbach's $a=.80)$ and ranged from 25 to 80 . A set of 
18 neutral words (Appendix B $)$ was selected from the Syssau and Font (2005) norms and divided into two sub-lists of nine words each (sublists, Neut1 and Neut2).

Again, as in Experiment 1, we found a significant difference across the two age groups in terms of sum total TAS-20 scores, $t(58)$ $=3.69, d=0.95, p<.01$, with the old group scoring higher. Notably, this difference was, again, driven by significant differences between the two groups in terms of the DIF and EOT factors of alexithymia, $t(58)=1.79, d=0.46, p=.08$ and $t(58)=5.86, d=0.58, p<.01$, respectively (again, see Table 6 ).

Table 6. Experiment 2: Descriptive statistics (means [SD]) according to age group

\section{Younger adults}

Age (yrs)

Education (yrs)

MMSE

HADS

TAS-20 total

DIF

DDF

EOT

$$
41.17(5.04) * *
$$$$
10.20(2.72)
$$

$28.83(1.28)$

$10.60(3.53)$

$45.07(7.48) * *$

$15.73(5.98)^{ \pm}$

$13.17(3.87)$

15.80 (3.47)**

\section{Older adults}

86.80 (5.11)**

$8.72(2.81)$

$28.90(1.36)$

9.30 (2.49)

$52.83(5.54) * *$

$18.53(6.18)^{ \pm}$

$14.53(3.21)$

$24.60(6.14) * *$

MMSE, Mini-mental State Exam; HADS, Hospital Anxiety Depression Scale, TAS-20 total, Toronto Alexithymia Scale-20, total score; DIF, difficulties in identifying feelings and distinguishing them from bodily sensations of emotional arousal, Alexithymia Factor 1; DDF, difficulties in describing one's own feelings, Alexithymia Factor 2; and EOT, a stimulus-bound, externally oriented cognitive style (i.e., operational thinking), Alexithymia Factor 3.

** Denotes significance across groups lower than the .01 level.

${ }^{+}$Denotes significant across groups at the .10 level.

\section{Results and discussion}

An initial analysis, again, was conducted to examine the possibility of primacy or recency effects. We found no significant contribution of serial item order. Then, as in Experiment 1, we ran a correlational analysis of the pertinent variables (without age, as it is analysed as a dichotomous variable; see Table 8). Again, the results of this correlational analysis will be discussed in conjunction with our regression analyses below. 
Next, we performed two sets (one set for TBR items; one set for TBF items) of hierarchical multiple regression analyses: in each set, one focused on the sum total alexithymia scores, the other on the alexithymia factors. As in Experiment 1, given that none of the correlations between depression/anxiety and the other independent variables exceeds .40 , it is unlikely that there would be any issues of multicollinearity (Voss, 2005), but we still included depression/anxiety as control variables. Age was also included in both regressions as a dummy variable (younger vs. older adults). Again, in both sets of regressions, no predictors were taken out later on and all interaction terms were included. We, again, transformed the data, taking the natural log of each variable prior to analysis.

For the sum total alexithymia hierarchical multiple regression analyses, the variables were entered in three steps. In step 1 , the proportion of TBR or TBF items recalled was entered as the dependent variables, and (1) depression and (2) anxiety scores were entered as the independent variables. In step 2, age was entered into the step 1 equation. In step 3, we entered the sum total alexithymia scores (see Table 7 for the means and standard deviations according to TBR/TBF items, low/high alexithymia and age).

Table 7. Proportions and standard deviations for recall of neutral words according to TBR/TBF items, low/high alexithymia and age

Younger adults Low alex.

TBR recall TBF recall $0.44(0.17)$ $0.14(0.08)$
High alex.

$0.56(0.14)$
Older adults Low alex.

$0.25(0.15)$

$0.09(0.10)$
High alex.

$0.20(0.09)$ $0.15(0.12)$

TBR, to-be-remembered; TBF, to-be-forgotten; Alex, alexithymia.

The variables in the alexithymia factors hierarchical multiple regression analyses were also entered in three steps. In step 1 , the proportion of TBR or TBF items recalled was entered as the dependent variables, and (1) depression and (2) anxiety scores were entered as independent variables. In step 2, age was entered into the step 1 equation. In step 3, we entered the alexithymia factors: DIF, DDF and EOT (see Table 8 for correlations between all the regression variables). 
NOT THE PUBLISHED VERSION; this is the author's final, peer-reviewed manuscript. The published version may be accessed by following the link in the citation at the bottom of the page.

Table 8. Experiment 2: Correlation values between regression variables for neutral material

1. TBF items recalled

2. TBR items recalled

3. Total items recalled

4. Anxiety scores

5. Depression scores

6. TAS total score

7. DIF

8. DDF

$$
\begin{array}{ccccccccc}
\mathbf{1} & \mathbf{2} & \mathbf{3} & \mathbf{4} & \mathbf{5} & \mathbf{6} & \mathbf{7} & \mathbf{8} & \mathbf{9} \\
1 & .07 & .55^{* *} & -.09 & .05 & .16 & .21 & .22 & .05 \\
& 1 & .88 * * & .00 & .20 & -.22 & -.02 & .09 & \\
& & 1 & -.04 & .20 & -.11 & .09 & .02 & -.32 * * \\
& & 1 & .37 * * & .26 * & .29 * & .17 & .21 \\
& & & 1 & .21 & .30_{-}^{*} & .39 * * & -.01 \\
& & & & 1 & .91 * * & .77 * * & .88^{* *} \\
& & & & & 1 & .70^{* *} & .66 * *
\end{array}
$$

9. EOT

Note: We computed a Split-Half score to examine the reliability of these results. We found moderate to good reliability with a Spearman-Brown Coefficient of .64. DIF, difficulties in identifying feelings and distinguishing them from bodily sensations of emotional arousal, Alexithymia Factor 1; DDF, difficulties in describing one's own feelings, Alexithymia Factor 2; and EOT, a stimulus-bound, externally oriented cognitive style (i.e., operational thinking), Alexithymia Factor 3.

* Denotes significance across groups lower than the .05 level.

** Denotes significance across groups lower than the .01 level.

In terms of TBF intrusions, we found no significant predictors or interaction effects with age, total alexithymia or the alexithymia factors (see Table 9). As for recall of TBR items, we found that only age negatively predicted recall. The overall alexithymia scores did not predict recall of TBR items (see Table 10). However, when we computed our subsequent hierarchical multiple regressions with the factors of alexithymia, not only did age remain significant, but we also found that the DIF factor of alexithymia significantly predicted the recall of TBR material, but in the opposite direction of age. That is, in general, older adults appeared to have more difficulty retrieving neutral material. Alternatively, adults with greater difficulty in identifying emotions were better at retrieving neutral material, suggesting a unique benefit for those scoring high on this particular factor of alexithymia (again, see Table 10). As far as we know, we are the first to find such a benefit for neutral material (but see Vermeulen et al., 2010). Like in Experiment 1, our correlational analyses revealed a negative association between the recall of TBR items and the EOT factor of alexithymia. We discuss the importance of these correlations further in the General Discussion. 
NOT THE PUBLISHED VERSION; this is the author's final, peer-reviewed manuscript. The published version may be accessed by following the link in the citation at the bottom of the page.

Table 9. Experiment 2: Regression values with recall of TBF intrusions as the dependent variable for neutral material

\section{Predictors}

Sum total alexithymia

Anxiety

Depression

Age

Sum total alexithymia score

Sum total alexithymia score $x$ age

Alexithymia factors

Anxiety

Depression

Age

DIF

DDF

EOT

DIF $\times$ age

DDF $\times$ age

EOT $\times$ age

\begin{tabular}{lrrrr}
\multicolumn{1}{c}{$\boldsymbol{\beta}$} & \multicolumn{1}{c}{$\mathbf{R}^{\mathbf{2}}$} & \multicolumn{1}{c}{$\mathbf{\Delta R}^{\mathbf{2}}$} & \multicolumn{1}{c}{$\mathbf{t}$} & \multicolumn{1}{c}{$\mathbf{p}$} \\
& & & & \\
-.01 & .00 & - & -.04 & .97 \\
-.14 & .10 & .10 & -.58 & .57 \\
-.29 & .10 & .00 & -.80 & .44 \\
.44 & .15 & .05 & 1.18 & .25 \\
.10 & .16 & .01 & .50 & .62 \\
& & & & \\
.08 & .00 & - & .31 & .76 \\
-.16 & .01 & .01 & -.62 & .54 \\
-.27 & .01 & .00 & -1.13 & .27 \\
-.22 & .05 & .04 & -.63 & .53 \\
.25 & .08 & .03 & .93 & .36 \\
.36 & .12 & .04 & 1.07 & .29 \\
.03 & .12 & .00 & .10 & .92 \\
.30 & .15 & .03 & 1.12 & .27 \\
-.37 & .22 & .07 & -1.66 & .11
\end{tabular}

DIF, difficulties in identifying feelings and distinguishing them from bodily sensations of emotional arousal, Alexithymia Factor 1 ; DDF, difficulties in describing one's own feelings, Alexithymia Factor 2; and EOT, a stimulus-bound, externally oriented cognitive style (i.e., operational thinking), Alexithymia Factor 3.

Table 10. Experiment 2: Regression values with recall of TBR items as the dependent variable for neutral material

\section{Predictors}

Sum total alexithymia

Anxiety

Depression

Age

Sum total alexithymia score

Sum total alexithymia score $x$ age

Alexithymia factors

Anxiety

Depression

Age

DIF

DDF

EOT

DIF $\times$ age

DDF $\times$ age

EOT $\times$ age

\begin{tabular}{lrrrr}
\multicolumn{1}{c}{$\boldsymbol{\beta}$} & \multicolumn{1}{c}{$\mathbf{R}^{2}$} & \multicolumn{1}{c}{$\mathbf{R}^{2}$} & \multicolumn{1}{c}{$\mathbf{t}$} & \multicolumn{1}{c}{$\mathbf{p}$} \\
& & & & \\
-.09 & .01 & - & -.74 & .46 \\
.15 & .08 & .07 & 1.21 & .23 \\
-.76 & .61 & .53 & -6.55 & $.01_{-}^{*}$ \\
.16 & .71 & .10 & 1.36 & .18 \\
-.05 & .71 & .00 & -.39 & .70
\end{tabular}

$\begin{array}{lllll}-.13 & .01 & - & -1.07 & .29\end{array}$

$\begin{array}{lllll}.11 & .08 & .07 & .91 & .37\end{array}$

$\begin{array}{lllll}-.64 & .52 & .44 & -5.09 & .01 *\end{array}$

$\begin{array}{lllll}.47 & .59 & .07 & 2.73 & .01 *\end{array}$

$\begin{array}{lllll}-.14 & .60 & .01 & -.97 & .34\end{array}$

$\begin{array}{lllll}-.22 & .61 & .01 & -1.34 & .19\end{array}$

$\begin{array}{lllll}-.06 & .65 & .04 & -.41 & .69\end{array}$

$\begin{array}{lllll}-.13 & .66 & .01 & -.92 & .36\end{array}$

$\begin{array}{lllll}-.08 & .66 & .00 & -.68 & .50\end{array}$

Cognition and Emotion, Vol 28 (May 23, 2014): pg. 442-459. DOI. This article is (c) Taylor \& Francis (Routledge) and permission has been granted for this version to appear in e-Publications@ Marquette. Taylor \& Francis (Routledge) does not grant permission for this article to be further copied/distributed or hosted elsewhere without the express permission from Taylor \& Francis (Routledge). 
NOT THE PUBLISHED VERSION; this is the author's final, peer-reviewed manuscript. The published version may be accessed by following the link in the citation at the bottom of the page.

DIF, difficulties in identifying feelings and distinguishing them from bodily sensations of emotional arousal, Alexithymia Factor 1; DDF, difficulties in describing one's own feelings, Alexithymia Factor 2; and EOT, a stimulus-bound, externally oriented cognitive style (i.e., operational thinking), Alexithymia Factor 3.

* Denotes significance of the predictor variable lower than the .05 level.

These results suggest that: (1) alexithymia and age do not impact the ability of adults to inhibit the recall of neutral material and (2) while advancing age impairs the ability to retrieve desired neutral material, greater difficulty in identifying emotions leads to better retrieval of desired neutral material. In total then, these results suggest that an increase in alexithymia scores results in a greater difficulty in controlling the inhibition and retrieval of emotional material (see Experiment 1), but may provide some degree of advantage in remembering neutral material.

\section{General Discussion}

Five goals motivated our research. First, we examined whether alexithymia influences the ability of adults to control the recall of negative TBF and TBR items. We found that as alexithymia scores increased, the ability to effectively recall wanted negative material and forget unwanted negative material declined. That is, those with higher alexithymia scores recalled more intrusions, but recalled fewer sought after negative items. These results suggest that, rather than simply an issue of successfully recalling negative material, the deficits associated with alexithymia represent a global decline in cognitive control: alexithymia impairs the recall of sought after negative material and impairs the ability to prevent the recall of unwanted negative material (cf. Luminet et al., 2006; Parker et al., 1993). These results suggest that when clinicians attempt to treat individuals with clinically relevant degrees of alexithymia, such as primary and comorbid alexithymia, they must take into consideration the broader cognitive control issues associated with alexithymia. Moreover, the present results suggest that alexithymia results in executive control deficits as well as, or as a result of, emotion processing deficits.

Second, we examined whether cognitive control of negative material was reduced in advanced age. Indeed, a number of studies using the directed forgetting paradigm have shown that ageing decreases the ability of individuals to intentionally forget unwanted 
memories (Dywan \& Murphy, 1996; Hasher et al., 1999; Jacoby et al., 2005; Zacks et al., 1996; but see Castel, Farb, \& Craik, 2007;

Sahakyan et al., 2008). Alternatively, in terms of negative material, recent researchers have found what they term, a "positivity effect" (Charles et al., 2003; Mather \& Carstensen, 2005; ): older adults are better able to control and forget negative material, thereby facilitating emotional well-being (see also Castel et al., 2007). In general, our results support the latter: overall, adults (including older adults) not only exhibited a trend towards having fewer intrusions of negative items, but also recalled fewer "sought" after negative items. These results suggest that adults may be particularly adapted at controlling whether they recall or not negative material (see also Mather \& Knight, 2005). However, the fact that we found similar results in terms of retrieving sought after items for neutral material raises questions of the validity of this explanation. We discuss this further below.

Third, we explored whether the effects of alexithymia on cognitive control were due primarily to one or more of the three alexithymia factors (DIF, DDF, EOT), as this has yet to be systematically investigated. While a few studies have generally not found emotional or cognitive differences across the three factors of alexithymia (e.g., Luminet et al., 2006; Vermeulen et al., 2010, but see Davydov, Luminet, \& Zech, 2013; Nielson, 2012; Vermeulen \& Luminet, 2009), the present results suggest that EOT, in particular, may be important in understanding how individuals inhibit negative material. Indeed, recent research indicates that EOT may play an important role in how individuals cognitively process emotional material (Davydov et al., 2013; Nielson, 2012). While some researchers have found EOT to be negatively associated with intrusions (Luminet et al., 2004) and, in some cases, help improve recognition of previously studied material (Vermeulen \& Luminet, 2009), neither of these studies instructed participants to "forget" or control what they remember or not remember. Thus, while under some circumstances individuals with high levels of EOT may ruminate less and/or have an easier time recalling previously studied material, the present results suggest that individuals who score high on the EOT factor of alexithymia have greater difficulty intentionally inhibiting negative material. The different findings between our present results and others in terms of EOT underscore the importance of examining both aspects of cognitive control: retrieval and inhibition. One 
possibility for this lack of cognitive control may be that by focusing cognitive resources "externally", individuals who score higher on the EOT factor of alexithymia are less able to exert "internal" cognitive control. Alexithymia may reduce the availability of the necessary cognitive resources needed to successfully avoid irrelevant, negative material. Future research is needed to better examine this possibility.

These results suggest that mental health treatments, especially approaches that focus attention on internal experiences (e.g., mindfulness training, Didonna, 2009), may be very beneficial for individuals with clinically relevant degrees of alexithymia, such as primary and comorbid alexithymia. More research is necessary, but what is becoming apparent is the need to examine alexithymia, not just in terms of the sum total score but also in terms of its subscales to better differentiate, diagnose and reduce the complications associated with alexithymia.

Fourth, and critically, while we found that older adults did exhibit higher levels of alexithymia, we found no interaction between alexithymia (or any of the alexithymia factors) and age for negative material, suggesting that, while higher alexithymia scores might impair the ability to control the recall of negative material, it does not do so as a function of age (Pasini et al., 1992). Thus, based on these results, while older adults may have, in general, higher alexithymia scores than younger adults, their inability to forget or ignore irrelevant negative information is more affected by alexithymia than age. However, it is possible that the "positivity effect" found in previous research (Charles et al., 2003; Mather \& Carstensen, 2005;) may act as a protective shield from the detrimental impact of alexithymia over time. Future research should specifically examine if and in what ways the "positivity effect" may ameliorate the emotional and cognitive deficits associated with alexithymia.

Lastly, we were interested in whether our results with negative material would extend to or differ when using neutral material. Most research in the past has found the emotional and cognitive deficits of alexithymia to be associated only with emotional material. Our results further support this contention. Not only did alexithymia fail to negatively impact the ability of younger and older adults to control the recall of neutral material, but we actually found that the DIF factor of 
alexithymia improved the recall of sought after neutral material. (However, as with negative material, there is some evidence that the EOT factor of alexithymia may also impair the ability of individuals to recall sought after neutral material.4) This mnemonic benefit in terms of difficulty identifying feelings may occur for at least two reasons. First, it could be due to mood congruency/mood dependency effects. As it is difficult for them to identify emotions, those with greater alexithymia may perpetually be in a "neutral" mood thereby making neutral material more memorable and easier to subsequently recall. Second, the mnemonic benefit may occur because non-emotive material becomes more salient relative to emotional material for those with higher DIF scores (Meltzer \& Nielson, 2010). While future studies should further clarify the differential effects of the alexithymia factors on memory, the present results underscore the importance of studying the specific contributions of each alexithymic factor and to what extent their contributions differ when individuals process/cognitively control neutral and negative material.

As the results of Experiment 2 with neutral material mirrored the age effects in Experiment 1 with negative material, a possible alternative explanation for the results with the older adults and negative material is that there was a general inability to recall the information, regardless of the instructions. We suspect that both the "positivity effect" and a general retrieval failure played roles in the pattern of findings. This possibility needs further investigation. In addition, a direct comparison of the recall of negative and neutral material within a single experiment would be valuable in future studies. While that was not our goal, such a comparison may provide additional nuances into the differences inherent when recalling emotive vs. non-emotive material that was impossible to discern in our crossexperiment comparison.

It is also worth noting that, given our primary interest in alexithymia and the cognitive control of negative material due to their critical roles in the ability of older adults to remain emotionally healthy, it is unknown whether our results would extend to positive material or whether cognitive control, such as that involved in the ability to "intentionally forget", is related more generally to emotion regulation (but see Mather \& Carstensen, 2005). Lastly, future studies should also include or control for individual differences, such as permission has been granted for this version to appear in e-Publications@Marquette. Taylor \& Francis (Routledge) does not grant permission for this article to be further copied/distributed or hosted elsewhere without the express permission from Taylor \& Francis (Routledge). 
emotion suppression and reappraisal, to gain a better understanding of the extent to which those variables mediate the relation between alexithymia and cognitive control.

Lastly, we would like to mention one methodological limitation of the present study: our recruitment procedure. Some might have concerns that, for the most part, our younger adults were recruited from a fitness centre whereas the older adults were primarily recruited from retirement homes. There is the possibility that a more active lifestyle in the younger adults could have benefited them in these tasks relative to the possibly more sedentary older adults (see, e.g., Colcombe \& Kramer, 2003; Erickson et al., 2011). While an evaluation of such effects would be of future value, it does not appear that lifestyle differences played a significant role in the present results as we found no fundamental differences in basic cognitive abilities across age groups: all participants exhibited normal cognitive functioning.

\section{Conclusion}

Overall, these results suggest that while alexithymia and the "externally oriented thinking" factor of alexithymia impair the ability of adults to cognitively control negative material, the "difficulty in identifying emotions" factor of alexithymia may actually help individuals retrieve neutral material. These results help illuminate the costs and benefits of alexithymia; alexithymia may negatively impact the cognitive control of negative material, but may facilitate the cognitive control of neutral material. Critically, however, in terms of guiding future treatment of clinically relevant degrees of alexithymia, such as primary and comorbid alexithymia, the present results indicate that clinicians should give special consideration to alexithymia's negative effects on the cognitive control (both inhibition and retrieval) of negative material.

\section{Appendix A. The Negative Words (In French And English) Used In Experiment 1}

$\begin{array}{ll}\text { Original words English translations } \\ \text { Sombre } & \text { Sullen } \\ \text { Fatigue } & \text { Fatigue } \\ \text { Douleur } & \text { Pain }\end{array}$

Cognition and Emotion, Vol 28 (May 23, 2014): pg. 442-459. DOI. This article is (c) Taylor \& Francis (Routledge) and permission has been granted for this version to appear in e-Publications@Marquette. Taylor \& Francis (Routledge) does not grant permission for this article to be further copied/distributed or hosted elsewhere without the express permission from Taylor \& Francis (Routledge) 
NOT THE PUBLISHED VERSION; this is the author's final, peer-reviewed manuscript. The published version may be accessed by following the link in the citation at the bottom of the page.

$\begin{array}{ll}\text { Oubli } & \text { Lapse } \\ \text { Canon } & \text { Cannon } \\ \text { Serpent } & \text { Snake } \\ \text { Cigare } & \text { Cigar } \\ \text { Pénurie } & \text { Shortage } \\ \text { Maladie } & \text { Illness } \\ \text { Crise } & \text { Crisis } \\ \text { Haine } & \text { Hate } \\ \text { Diable } & \text { Devil } \\ \text { Couteau } & \text { Knife } \\ \text { Armée } & \text { Army } \\ \text { Chagrin } & \text { Sadness } \\ \text { Faute } & \text { Mistake } \\ \text { Danger } & \text { Danger } \\ \text { Crainte } & \text { Disquiet }\end{array}$

\section{Appendix B. The Neutral Words (In French And English) Used In Experiment 2}

$\begin{array}{ll}\text { Original words } & \text { English translations } \\ \text { Balai } & \text { Broom } \\ \text { Table } & \text { Table } \\ \text { Échelle } & \text { Ladder } \\ \text { Feuille } & \text { Leaf } \\ \text { Porte } & \text { Door } \\ \text { Bonnet } & \text { Bonnet } \\ \text { Doigt } & \text { Finger } \\ \text { Chemise } & \text { Shirt } \\ \text { Bûche } & \text { Wood } \\ \text { Timbre } & \text { Stamp } \\ \text { Peigne } & \text { Comb } \\ \text { Horloge } & \text { Clock } \\ \text { Tasse } & \text { Cup } \\ \text { Cahier } & \text { Notebook } \\ \text { Boîte } & \text { Box } \\ \text { Panier } & \text { Basket } \\ \text { Cintre } & \text { Hanger } \\ \text { Tonneau } & \text { Barrel }\end{array}$

\section{Notes}

${ }^{1}$ Traditionally, this type of cognitive control has been couched in terms of inhibition (Barnier et al., 2007;; Bjork, 1989; Bjork \& Bjork, 2003;

Cognition and Emotion, Vol 28 (May 23, 2014): pg. 442-459. DOI. This article is (c) Taylor \& Francis (Routledge) and permission has been granted for this version to appear in e-Publications@ Marquette. Taylor \& Francis (Routledge) does not grant permission for this article to be further copied/distributed or hosted elsewhere without the express permission from Taylor \& Francis (Routledge). 
Geiselman \& Bagheri, 1985; MacLeod, 1998 1999; Power et al., 2000; Wilson \& Kipp, 1998). This inhibition, according to the directsuppression model, is an executive control process whereby target items inhibited directly (Levy \& Anderson, 2002). However, recent research suggests that the impaired recall of TBF items may better be framed in terms of context change (Sahakyan \& Foster, 2009; Sahakyan \& Kelley, 2002; Sahakyan et al., 2008). That is, the participants make a mental context change between items instructed to be forgotten and those instructed to be remembered. As the final recall test context better matches the to-be-remembered items, individuals are better able to recall these, while forgetting the others. Here, however, we remain agnostic to the ultimate mechanisms driving the directed forgetting effect. Rather, we are primarily interested in whether, when instructed to forget, participants are able to forget (by whichever mechanism) the items instructed to be forgotten.

${ }^{2}$ Given our low Cronbach's $a$ scores for the depression and anxiety scales comprising the HADS measure, we entered them into our regression models separately.

${ }^{3}$ See note 2.

${ }^{4}$ It is worth mentioning, though, that the evidence suggesting that EOT also influences the ability to control neutral material is based upon our correlational analyses. All results from our correlational analyses, especially those that differ from our regression analyses, should be interpreted with caution. Unlike our regression analyses, our correlational analyses fail to control for anxiety and depression.

\section{References}

Bagby, R. M., Parker, J. D. A., \& Taylor, G. J. (1994). The twenty-item Toronto Alexithymia Scale - I. Item selection and cross-validation of the factor structure. Journal of Psychosomatic Research, 38, 23-32. doi:10.1016/0022-3999(94)90005-1

Bagby, R. M., Taylor, G. J., \& Parker, J. D. A. (1994). The twenty-item Toronto-Alexithymia-Scale II. Convergent, discriminant, and concurrent validity. Journal of Psychosomatic Research, 38, 33-40. doi:10.1016/0022-3999(94)90006-X

Barnier, A. J., Conway, M. A., Mayoh, L., Speyer, J., Avizmil, O., \& Harris, C. B. (2007). Directed forgetting of recently recalled autobiographical memories. Journal of Experimental Psychology: General, 136, 301322. doi:10.1037/0096-3445.136.2.301

Cognition and Emotion, Vol 28 (May 23, 2014): pg. 442-459. DOI. This article is (c) Taylor \& Francis (Routledge) and permission has been granted for this version to appear in e-Publications@Marquette. Taylor \& Francis (Routledge) does not grant permission for this article to be further copied/distributed or hosted elsewhere without the express permission from Taylor \& Francis (Routledge). 
NOT THE PUBLISHED VERSION; this is the author's final, peer-reviewed manuscript. The published version may be

accessed by following the link in the citation at the bottom of the page.

Basden, B. H., \& Basden, D. R. (1996). Directed forgetting: Further comparisons of the item and list methods. Memory, 4, 633-653. doi: $10.1080 / 741941000$

Basden, B. H., Basden, D. R., \& Gargano, G. J. (1993). Directed forgetting in implicit and explicit memory tests: A comparison of methods. Journal of Experimental Psychology: Learning, Memory, \& Cognition, 19, 603616. doi:10.1037/0278-7393.19.3.603

Bjork, R. A. (1989). Retrieval inhibition as an adaptive mechanism in human memory. In H. L. Roediger III \& F. I. M. Craik (Eds.), Varieties of memory an consciousness: Essays in honour of Endel Tulving (pp. 309-330). Hillsdale, NJ: Erlbaum.

Bjork, E. L., \& Bjork, R. A. (2003). Intentional forgetting can increase, not decrease, residual influences of to-be-forgotten information. Journal of Experimental Psychology: Learning, Memory, and Cognition, 29, 524531. doi:10.1037/0278-7393.29.4.524

Bjork, E. L., Bjork, R. A., \& Anderson, M. C. (1998). Varieties of goal-directed forgetting. In J. M. Golding \& C. M. MacLeod (Eds.), Intentional forgetting: Interdisciplinary approaches (pp. 103-137). Mahwah, NJ: Erlbaum.

Carstensen, L. L., \& Mikels, J. A. (2005). At the intersection of emotion and cognition: Aging and the positivity effect. Current Directions in Psychological Science, 14, 117-121. doi:10.1111/j.09637214.2005.00348.x

Castel, A. D., Farb, N. A. S., \& Craik, F. I. (2007). Memory for general and specific value information in younger and older adults: Measuring the limits of strategic control. Memory \& Cognition, 35, 689-700. doi: $10.3758 / B F 03193307$

Charles, S. T., \& Carstensen, L. L. (2007). Emotion regulation and aging. In J. J. Gross (Ed.), Handbook of emotion regulation (pp. 307-327). New York, NY: The Guilford Press.

Charles, S. T., Mather, M., \& Carstensen, L. L. (2003). Aging and emotional memory: the forgettable nature of negative images for older adults. Journal of Experimental Psychology: General, 132, 310-324. doi: $10.1037 / 0096-3445.132 .2 .310$

Colcombe, S., \& Kramer, A. F. (2003). Fitness effects on the cognitive function of older adults: A meta-analytic study. Psychological Science, 14, 125-130. doi:10.1111/1467-9280.t01-1-01430

Davydov, D. M., Luminet, O., \& Zech, E. (2013). An externally oriented style of thinking as a moderator of responses to affective films in women. International Journal of Psychophysiology, 87, 152-164. doi: 10.1016/j.ijpsycho.2012.12.003

Derouesné, C., Poiteneau, J., Hugonot, L., Kalafat, M., Dubois, B., \& Laurent, B. (1999). Le Mini-Mental State Examination (MMSE): Un outil pratique permission has been granted for this version to appear in e-Publications@Marquette. Taylor \& Francis (Routledge) does not grant permission for this article to be further copied/distributed or hosted elsewhere without the express permission from Taylor \& Francis (Routledge). 
pour l'évaluation de l'état cognitif des patients par le clinicien [The Mini-Mental State Examination (MMSE): A useful method for the evaluation of the cognitive status of patients by the clinician]. $L a$ Presse Médicale, 28, 1141-1148. Retrieved from http://europepmc.org/abstract/MED/10399508

Didonna, F. (2009). Mindfulness and obsessive-compulsive disorder: Developing a way to trust and validate one's internal experience. In $\mathrm{F}$. Didonna (Ed.), Clinical handbook of mindfulness (pp. 189-219). New York, NY: Springer Science.

Dressaire, D., \& Brouillet, D. (2006). Effets de la vie en institution des personnes âgées sur leurs stratégies de faire face et sur leur difficulté à verbaliser leurs emotions [The effects of institutional care on older adults' coping strategies and ability to verbalize their emotions]. Bulletin de Psychologie, 59, 605-613. doi:10.3917/bupsy.486.0605

Dywan, J., \& Murphy, W. E. (1996). Aging and inhibitory control in text comprehension. Psychology and Aging, 11, 199-206. doi: $10.1037 / 0882-7974.11 .2 .199$

Erickson, K. I., Voss, M. W., Prakash, R. S., Basak, C., Szabo, A., Chaddock, L., ... Kramer, A. F. (2011). Exercise training increases size of hippocampus and improves memory. Proceedings of the National Academy of Sciences of the United States of America, 108, 30173022. doi:10.1073/pnas.1015950108

Feiguine, R. J., Hulihan, D. M., \& Kinsman, R. A. (1982). Alexithymic asthmatics: Age and alexithymia across the life span. Psychotherapy and Psychosomatics, 37, 185-188. doi:10.1159/000287571

Ferrand, L. (2001). Normes d'associations verbales pour 260 mots "abstraits" [The standard verbal associations for 260 "abstract" words]. L'Année Psychologique, 101, 683-721. Retrieved from http://www.persee.fr/web/revues/home/prescript/article/psy 0003$\underline{50332001 \text { num } 101429575}$

Ferrand, L., \& Alario, F.-X. (1998). Normes d'associations verbales pour 366 noms d'objets concrets [The standard verbal associations for 366 names of concrete objects]. L'Année Psychologique, 98, 659-709. Retrieved from http://www.persee.fr/web/revues/home/prescript/article/psy 0003$\underline{5033} 1998$ num $98 \quad 4 \quad 28564$

Friedman, S., Samuelian, J.-C., Lancrenon, S., Even, C., \& Chiarelli, P. (2001). Three dimensional structure of the hospital anxiety and depression scale in a large French primary care population suffering from major depression. Psychiatry Research, 104, 247-257. doi:10.1016/S0165-1781(01)00309-2

Cognition and Emotion, Vol 28 (May 23, 2014): pg. 442-459. DOI. This article is (C) Taylor \& Francis (Routledge) and permission has been granted for this version to appear in e-Publications@Marquette. Taylor \& Francis (Routledge) does not grant permission for this article to be further copied/distributed or hosted elsewhere without the express permission from Taylor \& Francis (Routledge). 
NOT THE PUBLISHED VERSION; this is the author's final, peer-reviewed manuscript. The published version may be

accessed by following the link in the citation at the bottom of the page.

Geiselman, R. E., \& Bagheri, B. (1985). Repetition effects in directed forgetting: Evidence of retrieval inhibition. Memory \& Cognition, 13, 57-62. doi:10.3758/BF03198444

Gross, J. J., Carstensen, L. L., Pasupathi, M., Tsai, J., Skorpen, C. G., \& Hsu, A. Y. (1997). Emotion and aging: Experience, expression, and control. Psychology and Aging, 12, 590-599. doi:10.1037/0882-7974.12.4.590

Gunzelmann, T., Kupfer, J., \& Brähler, E. (2002). Alexithymia in the elderly general population. Comprehensive Psychiatry, 43, 74-80. doi: $10.1053 /$ comp.2002.29855

Hasher, L., Zacks, R. T., \& May, C. P. (1999). Inhibitory control, circadian arousal, and age. In D. Gopher \& A. Koriat (Eds.), Attention and performance XVII, cognitive regulation of performance: Interaction of theory and application (pp. 653-675). Cambridge, MA: MIT Press.

Hendryx, M. S., Haviland, M. G., \& Shaw, D. G. (1991). Dimensions of alexithymia and their relationships to anxiety and depression. Journal of Personality Assessment, 56, 227-237. doi:10.1207/s15327752jpa5602_4

Jacob, S., \& Hautekeete, M. (1998). Alexithymia and memory: A more rigorous criterion for acceptance of recognition tasks? Encephale, 24, 199-204.

Jacoby, L. L., Bishara, A. J., Hessels, S., \& Toth, J. P. (2005). Aging, subjective experience, and cognitive control: Dramatic false remembering by older adults. Journal of Experimental Psychology: General, 134, 131-148. doi:10.1037/0096-3445.134.2.131

Krystal, H. (1995). Trauma and aging: A thirty-year follow-up. In C. Caruth (Ed.), Trauma: Explorations in memory (pp. 76-99). Baltimore, MD: The Johns Hopkins University Press.

Lepine, J. P. (1985). Evaluation de l'anxiété et de la dépression chez les patients hospitalizes dans un service de médecine interne [Evaluation of anxiety and depression among patients hospitalized on an internal medicine service]. Annales Médico Psychologiques, 143, 175-189. Retrieved from http://www.ncbi.nlm.nih.gov/pubmed/4037594

Levy, B. J., \& Anderson, M. C. (2002). Inhibitory processes and the control of memory retrieval. Trends in Cognitive Sciences, 6, 299-305. doi:10.1016/S1364-6613(02)01923-X

Loas, G., Corcos, M., Stephan, P., Pellet, J., Bizouard, P., Venisse, J. L., ... Jeammet, P. (2001). Factorial structure of the 20-item Toronto Alexithymia Scale confirmatory factorial analyses in nonclinical and clinical samples. Journal of Psychosomatic Research, 50, 255-261. doi:10.1016/S0022-3999(01)00197-0

Loas, G., Otmani, O., Fremaux, D., Lecercle, C., Duflot, M., \& Delahousse, J. (1996). Etude de la validité externe, de la fidélité et de la détermination des notes seuil des échelles d'alexithymie de Toronto

Cognition and Emotion, Vol 28 (May 23, 2014): pg. 442-459. DOI. This article is (c) Taylor \& Francis (Routledge) and permission has been granted for this version to appear in e-Publications@Marquette. Taylor \& Francis (Routledge) does not grant permission for this article to be further copied/distributed or hosted elsewhere without the express permission from Taylor \& Francis (Routledge). 
chez un groupe de malades alcooliques [External validity, reliability and basic score determination of the Toronto Alexithymia Scales (TAS and TAS-20) in a group of alcoholic patients]. L'Encéphale, 22, 35-40. Retrieved from http://www.ncbi.nlm.nih.gov/pubmed/8681873

Loas, G., Parker, J. D. A., Otmani, O., Verrier, A., \& Fremaux, D. (1997). Confirmatory factor analysis of the French translation of the twentyitem Toronto Alexithymia Scale. Perceptual and Motor Skills, 85, 1018. doi: 10.2466/pms.1997.85.3.1018

Luminet, O., Rime, B., Bagby, R. M., \& Taylor, G. J. (2004). A multimodal investigation of emotional responding in alexithymia. Cognition and Emotion, 18, 741-766. doi:10.1080/02699930341000275

Luminet, O., Vermeulen, N., Demaret, C., Taylor, G. J., \& Bagby, R. M. (2006). Alexithymia and levels of processing: Evidence for an overall deficit in remembering emotion words. Journal of Research in Personality, 40, 713-733. doi:10.1016/j.jrp.2005.09.001

Lundh, L.-G., Johnsson, A., Sundqvist, K., \& Olsson, H. (2002). Alexithymia, memory of emotion, emotional awareness and perfectionism. Emotion, 2, 361-379. doi: $10.1037 / 1528-3542.2 .4 .361$

MacLeod, C. M. (1998). Directed forgetting. In J. M. Golding \& C. M. MacLeod (Eds.), Intentional forgetting: Interdisciplinary approaches (pp. 1-57). Mahwah, NJ: Erlbaum.

MacLeod, C. M. (1999). The item and list methods of directed forgetting: Test differences and the role of demand characteristics. Psychonomic Bulletin \& Review, 6, 123-129. doi:10.3758/BF03210819

Mather, M., \& Carstensen, L. L. (2005). Aging and motivated cognition: The positivity effect in attention and memory. Trends in Cognitive Sciences, 9, 496-502. doi:10.1016/j.tics.2005.08.005

Mather, M., \& Knight, M. (2005). Goal-directed memory: The role of cognitive control in older adults' emotional memory. Psychology and Aging, 20, 554-570. doi:10.1037/0882-7974.20.4.554

Mattila, A. K., Salminen, J. K., Nummi, T., \& Joukamaa, M. (2006). Age is strongly associated with alexithymia in the general population. Journal of Psychosomatic Research, 61, 629-635. doi:10.1016/j.jpsychores.2006.04.013

Meltzer, M. A., \& Nielson, K. A. (2010). Memory for emotionally provocative words in alexithymia. Consciousness and Cognition, 19, 1062-1068. doi: $10.1016 /$ j.concog.2010.05.008

Montreuil, M., \& Pedinielli, J. L. (1995). Caractéristiques du traitement visuel parallèle chez des sujets sains alexithymiques. Application de la Toronto Alexithymia Scale et du test de saisie visuelle parallèle [Characteristics of parallel visual process in alexithymic healthy subjects. Application of the Toronto Alexithymia Scale and the parallel visual information processing test]. L'Encéphale, 21, 589-595.

Cognition and Emotion, Vol 28 (May 23, 2014): pg. 442-459. DOI. This article is (c) Taylor \& Francis (Routledge) and permission has been granted for this version to appear in e-Publications@Marquette. Taylor \& Francis (Routledge) does not grant permission for this article to be further copied/distributed or hosted elsewhere without the express permission from Taylor \& Francis (Routledge). 
Nemiah, J. C., Freyberger, H. J., \& Sifneos, P. E. (1976). Alexithymia: A view of the psychosomatic process. In O. W. Hill (Ed.), Modern trends in psychosomatic medicine (pp. 430-439). London: Butterworths.

New, B., Pallier, C., Ferrand, L., \& Matos, R. (2001). Une base de données lexicales du français contemporain sure internet: Lexique ${ }^{\mathrm{TM}}$ [A lexical database for contemporary French: LEXIQUE ${ }^{\mathrm{TM}}$ ]. L'Année Psychologique, 101, 447-462. doi:10.3406/psy.2001.1341

Nielson, K. A. (2012). The role of alexithymia and its subtypes in long-term emotional memory. Paper presented at the 16th European Conference on Personality, Trieste.

Paradiso, S., Vaidya, J. G., McCormick, L. M., Jones, A., \& Robinson, R. G. (2008). Aging and alexithymia association with reduced right rostral cingulate volume. American Journal of Geriatric Psychiatry, 16, 760769. doi:10.1097/JGP.0b013e31817e73b0

Parker, J. D. A., Taylor, G. J., \& Bagby, R. M. (1993). Alexithymia and the recognition of facial expressions of emotion. Psychotherapy and Psychosomatics, 59, 197-202. doi:10.1159/000288664

Parker, J. D. A., Taylor, G. J., \& Bagby, R. M. (2003). The 20-item Toronto Alexithymia Scale III: Reliability and factorial validity in a community population. Journal of Psychosomatic Research, 55, 269-275. doi:10.1016/S0022-3999(02)00578-0

Pasini, A., Chiaie, R. D., Seripa, S., \& Ciani, N. (1992). Alexithymia as related to sex, age, and educational level: Results of the Toronto Alexithymia Scale in 417 normal subjects. Comprehensive Psychiatry, 33, 42-46. doi: $10.1016 / 0010-440 \times(92) 90078-5$

Power, M. J., Dalgleish, T., Claudio, V., Tata, P., \& Kentish, J. (2000). The directed forgetting task: Application to emotionally valent material. Journal of Affective Disorders, 57, 147-157. doi:10.1016/S01650327(99)00084-1

Sahakyan, L., Delaney, P. F., \& Goodmon, L. B. (2008). "Oh, honey, I already forgot that": Strategic control of directed forgetting in older and younger adults. Psychology \& Aging, 23, 621-633. doi: $10.1037 / \mathrm{a} 0012766$

Sahakyan, L., \& Foster, N. L. (2009). Intentional forgetting of actions: Comparison of list-method and item-method directed forgetting. Journal of Memory and Language, 61, 134-152. doi: $10.1016 / j . j m l .2009 .02 .006$

Sahakyan, L., \& Kelley, C. M. (2002). A contextual change account of the directed forgetting effect. Journal of Experimental Psychology: Learning, Memory and Cognition, 28, 1064-1072. doi:10.1037/02787393.28.6.1064

Cognition and Emotion, Vol 28 (May 23, 2014): pg. 442-459. DOI. This article is (C) Taylor \& Francis (Routledge) and permission has been granted for this version to appear in e-Publications@Marquette. Taylor \& Francis (Routledge) does not grant permission for this article to be further copied/distributed or hosted elsewhere without the express permission from Taylor \& Francis (Routledge). 
NOT THE PUBLISHED VERSION; this is the author's final, peer-reviewed manuscript. The published version may be

accessed by following the link in the citation at the bottom of the page.

Sifneos, P. E. (1973). The prevalence of 'alexithymic' characteristics in psychosomatic patients. Psychotherapy and Psychosomatics, 22, 255262. doi: $10.1159 / 000286529$

Suslow, T., Kersting, A., \& Arolt, V. (2003). Alexithymia and incidental learning of emotional words. Psychological Reports, 93, 1003-1012. doi: 10.2466/pr0.2003.93.3f.1003

Syssau, A., \& Font, N. (2005). Évaluations des caractéristiques émotionnelles d'un corpus de 604 mots [Assessing the emotionality of 604 words]. Bulletin de Psychologie, 58, 361-367. doi:10.3917/bupsy.477.0361

Taylor, G. J., Bagby, R. M., \& Luminet, O. (2000). Assessment of alexithymia: Self-report and observer-rated measure. In J. D. A. Parker \& R. BarOn (Eds.), The handbook of emotional intelligence (pp. 301-319). San Francisco, CA: Jossey Bass.

Taylor, G. J., Bagby, M. R., \& Parker, J. D. A. (1997). Disorders of affect regulation. Alexithymia in medical and psychiatric illness. Cambridge: Cambridge University Press.

Taylor, G. J., Bagby, M. R., \& Parker, J. D. A. (2003). The 20-item Toronto Alexithymia Scale IV. Reliability and factorial validity in different languages and cultures. Journal of Psychosomatic Research, 55, 277283. doi:10.1016/S0022-3999(02)00601-3

Tombaugh, T. N. (2004). Trail making test A and B: Normative data stratified by age and education. Archives of Clinical Neuropsychology, 19, 203214. doi:10.1016/S0887-6177(03)00039-8

Van Der Linden, M., Coyette, F., Poitrenaud, J., Kalafat, M., Calicis, F., Wyns, C., ... les members du GREMEM. (2004). L'épreuve de rappel libre/rappel indicé à 16 items (RL/RI - 16) [Testing free recall and recognition of 16 cued items (RL/RI - 16)]. In M. V. D. Linden \& les membres du GREMEM (Eds.), L'évaluation des troubles de la mémoire [An evaluation of memory disorders] (pp. 25-47). Marseille, FR: Solal.

Vermeulen, N., \& Luminet, O. (2009). Alexithymia factors and memory performances for neutral and emotional words. Personality and Individual Differences, 47, 305-309. doi:10.1016/j.paid.2009.03.018

Vermeulen, N., Toussaint, J., \& Luminet, O. (2010). The influence of alexithymia and music on the incidental memory for emotion words. European Journal of Personality, 24, 551-568. doi:10.1002/per.758

Voss, D. S. (2005). Multicollinearity. In K. Kempf-Leonard (Ed.), Encyclopedia of social measurement (pp. 759-770). New York, NY: Elsevier.

Whetstone, T., Cross, M. D., \& Whetstone, L. M. (1996). Inhibition, contextual segregation, and subject strategies in list method directed forgetting. Consciousness and Cognition: An International Journal, 27, 395-417. doi: $10.1006 / \operatorname{ccog} .1996 .0025$

Cognition and Emotion, Vol 28 (May 23, 2014): pg. 442-459. DOI. This article is (c) Taylor \& Francis (Routledge) and permission has been granted for this version to appear in e-Publications@Marquette. Taylor \& Francis (Routledge) does not grant permission for this article to be further copied/distributed or hosted elsewhere without the express permission from Taylor \& Francis (Routledge). 
NOT THE PUBLISHED VERSION; this is the author's final, peer-reviewed manuscript. The published version may be accessed by following the link in the citation at the bottom of the page.

Wilson, S. P., \& Kipp, K. (1998). The development of efficient inhibition: Evidence from directed-forgetting tasks. Developmental Review, 18, 86-123. doi:10.1006/drev.1997.0445

Zacks, R. T., Hasher, L., \& Radvansky, G. (1996). Studies of directed forgetting in older adults. Journal of Experimental Psychology: Learning, Memory and Cognition, 22, 143-156. doi:10.1037/02787393.22.1.143

Zellner, M., \& Bäuml, K.-H. (2006). Inhibitory deficits in older adults: Listmethod directed forgetting revisited. Journal of Experimental Psychology: Learning, Memory, and Cognition, 32, 290-300. doi:10.1037/0278-7393.32.3.290 